\title{
Neuropsychological changes related to unilateral lenticulostriate infarcts
}

Oliver Godefroy, Marc Rousseaux, Jean Pierre Pruvo, Maryline Cabaret, Didier Leys

\begin{abstract}
According to previous studies, focal capsulostriatal lesions may produce aphasia, hemineglect, gestural apraxia, frontal lobe dysfunction, and memory impairment. A few reports of capsulostriate infarcts secondary to involvement of lenticulostriate arteries have confirmed that aphasia and hemineglect may occur whereas gestural apraxia, anosognosia and frontal-lobe symptoms are rare. Most studies used CT scan assessment and did not exclude possible associated lesions. Neuropsychological changes in 11 patients with lenticulostriate infarcts diagnosed by CT scan were prospectively investigated. MRI in five of the 11 patients showed an associated cortical lesion not seen on CT scan. Patients with pure lenticulostriate infarcts on MRI may exhibit aphasia of mild severity whereas Broca's aphasia, hemineglect, gestural apraxia, and anosognosia were only seen in the subgroup with associated cortical lesions. Aphasia in patients with pure lenticulostriate infarcts was characterised by prominent expressive and lexicosemantic task impairments. The results strongly suggest that cortical involvement is critical to the extent and severity of neuropsychological changes in patients with lenticulostriate infarcts.
\end{abstract}

$(\mathcal{F}$ Neurol Neurosurg Psychiatry 1994;57:480-485)

The development of new cerebral imaging techniques during the past 15 years has established the role of the basal ganglia in cognitive functions: focal capsulostriatal lesions may produce aphasia, ${ }^{1-15}$ hemineglect, ${ }^{4811-19}$ gestural and constructional apraxia, ${ }^{814} 17$ 20-22 frontal lobe dysfunction, ${ }^{1121423}$ and memory impairment. ${ }^{1423}$ In these studies, such cognitive deficits have been reported with different prevalence and severity. This makes difficult any attempt to establish clinicoanatomical correlations in patients with focal striatal lesions and prevents firm statements about the contribution of the basal ganglia to neuropsychological function. This could be for three main reasons ${ }^{24}$ : (1) there have only been a few prospective studies; (2) previous studies have included patients with various kinds of capsulostriatal lesions, although the nature of the lesion may contribute to the pattern of neuropsychological changes ${ }^{25}$; (3) previous studies used neuropsychological and radio- logical evaluations of different types. Evaluation of more homogeneous groups of patients would avoid this lack of consistency, and this could be achieved in studies focusing on patients with similar lesions. Among the various cerebral lesions, infarcts provide most advantages for study of the consequences of focal cerebral lesions because they abruptly disrupt previously undamaged neuronal networks and the territories of vascular supply are well defined. The blood supply of the basal ganglia mainly depends on the lenticulostriate arteries (deep branches of the middle cerebral artery), whereas the anterior choroidal artery supplies the posterior arm of the internal capsule, the globus pallidum, and the posterior part of the putamen. ${ }^{26}$ As both kinds of infarcts are generally studied without distinction under the common name of capsulostriate infarcts, they involve different neuronal structures: the lenticulostriate infarcts involve the putamen, the anterodorsal part of the head and the body of the caudate nucleus, the anterior part of the internal capsule, and the centrum ovale. The variability of the neuronal structures affected by both kinds of infarct could also account for the large range of neuropsychological deficits. This possibility supports the need for a precise inventory of the anatomical lesions in each patient. This requirement could be especially true in lenticulostriate infarcts as these are mainly due to a proximal occlusion of the middle cerebral artery $^{527}$ and are often associated with a cortical infarct. ${ }^{24}$

Previous studies focusing on capsulostriate infarcts within the territory of lenticulostriate arteries confirm the possible presence of apha$\operatorname{sia}^{5111314}$ and hemineglect, ${ }^{1,13,14}$ whereas constructional apraxia, gestural apraxia, anosognosia and frontal-like symptoms are rarely encountered. ${ }^{14}$ Except in the study of Weiller et $a l,{ }^{13}$ the radiological assessment mainly depended on CT scans and the structures involved were not precisely reported.

The aim of our study was to prospectively investigate neuropsychological changes in patients with lenticulostriate infarcts determined on MRI scans. The assessment of frontal lobe dysfunctions has been reported previously. ${ }^{24}$

\section{Patients and methods}

From the 927 patients admitted to the Lille University Hospital for an acute stroke over a nine month period (October 1989June 1990), 21 had an isolated unilateral 
lenticulostriate infarct on CT scan. Seven of them were excluded for at least one of the following reasons: previous or associated neurological or psychiatric disorders, history of head trauma with loss of consciousness, current neuroleptic or antiepileptic treatment, severe cardiac, respiratory, or renal failure, diabetes mellitus with hypoglycaemic episodes, alcoholism, or illiteracy.

MRI was performed eight weeks after the stroke onset in the remaining 14 patients with the methodology previously reported. ${ }^{24}$ Three patients were excluded after MRI because of lesions that were not seen on CT scans: two had another infarct located outside the territory of the ipsilateral middle cerebral artery, and one had white matter and periventricular hyperintensity scores higher than unity according to the criteria of Fazekas et al..$^{28}$ Thus 11 patients were actually included in the study. Six patients had a pure lenticulostriate infarct on MRI (pure group). In the remaining five patients, MRI showed another infarct not seen on CT scan (cortical associated lesion group) and located in the cortical territory of the ipsilateral middle cerebral artery (frontoinsulotemporal (two cases), insulofrontal (one case), frontoparietal (one case), temporoparietal (one case) (figure)). Nine patients were right handed and two were left handed": one in the pure group with leftbrain damage (case 3 ) and one in the cortical associated lesion group with right-brain damage (case 11). ${ }^{29}$ Controls were 11 right handed healthy volunteers from the community. All subjects were native French speakers. There was no significant difference in age and education level between patients and controls. Table 1 gives the demographic characteristics of the subjects and location of lesions.

Neuropsychological assessment was performed six to eight weeks after onset, but
Location of the two left (left) and the three right (right) cortical associated lesions revealed by MRI.
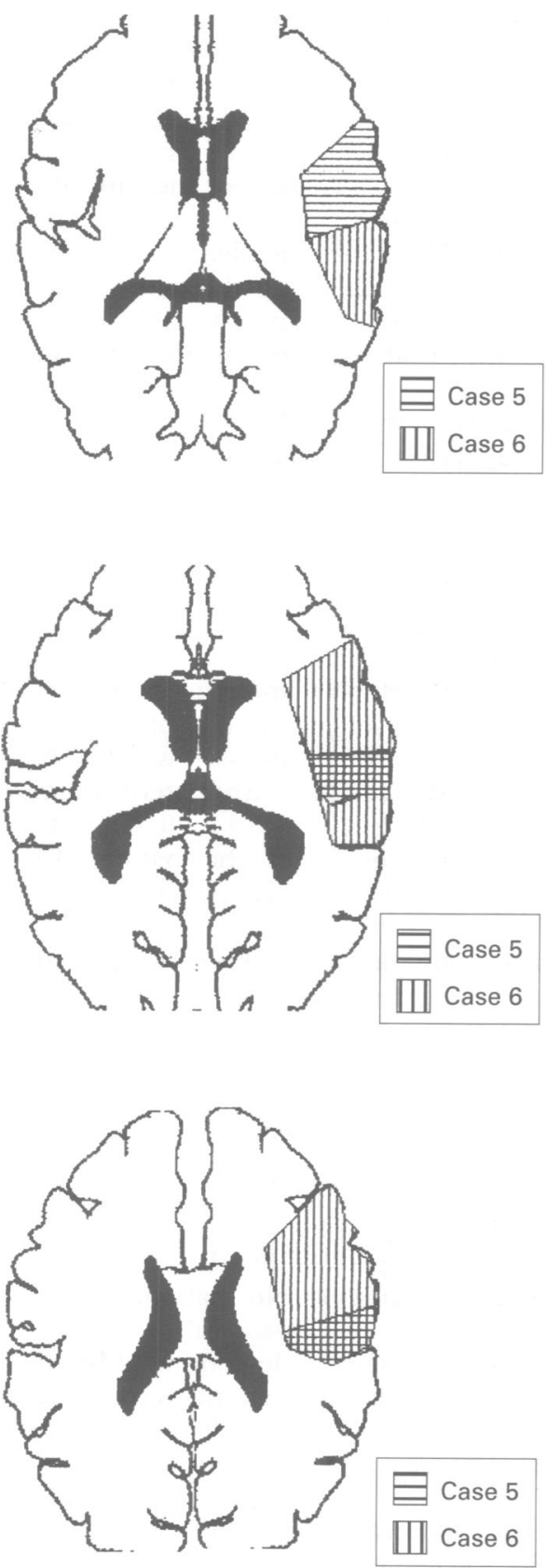
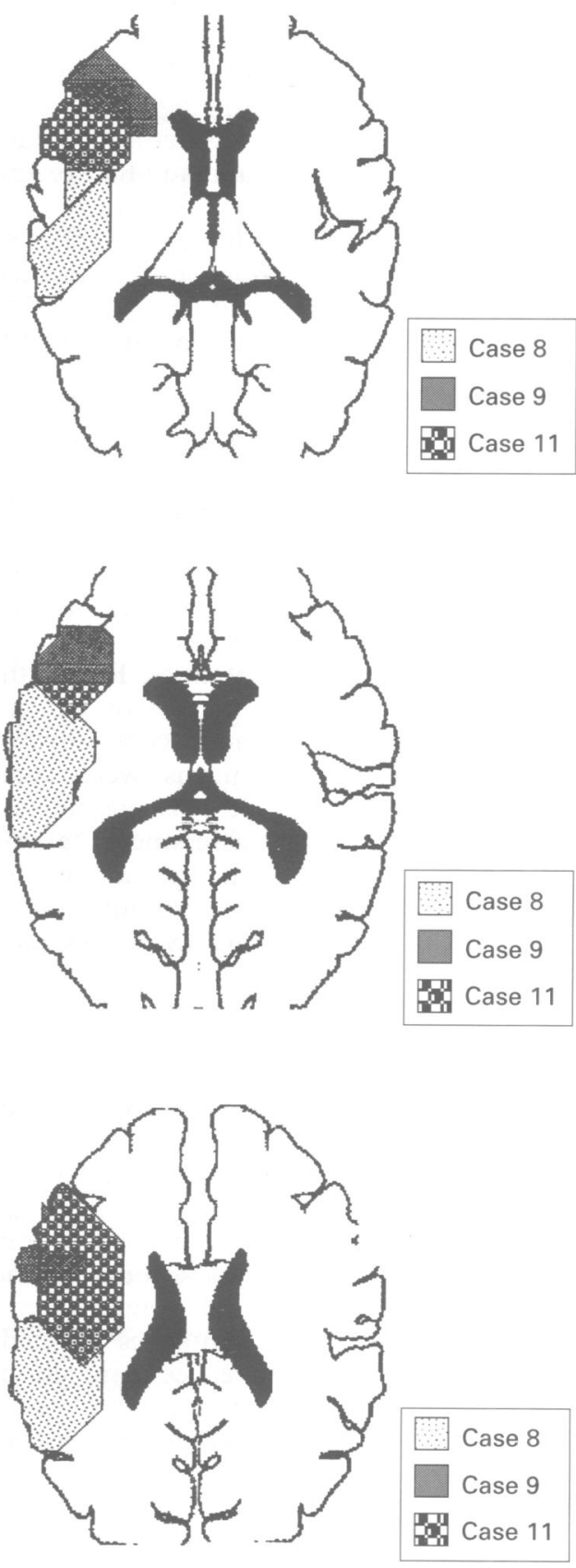
Table 1 Demographic characteristics of patients and controls and location of infarcts on MRI

\begin{tabular}{|c|c|c|c|c|c|}
\hline & \multicolumn{5}{|c|}{ Side of the infarct } \\
\hline & \multicolumn{2}{|c|}{ Pure LSI group } & \multicolumn{2}{|l|}{$C A L$ group } & \multirow[b]{2}{*}{ Controls } \\
\hline & Left & Right & Left & Right & \\
\hline $\begin{array}{l}\text { n } \\
\text { Age }(y)^{\star} \\
\text { Sex }(M / F) \text {. } \\
\text { Education level } \star^{\star} \\
\text { Right handedness } \ddagger^{\star} \\
\text { Caudate lesion } \\
\text { Putaminal lesion } \\
\text { Pallidal lesion } \\
\text { AAIC lesion } \\
\text { Centrum ovale lesion }\end{array}$ & $\begin{array}{l}4 \\
61(26-78) \\
2 / 2 \\
1(1-2) \\
8 \cdot 5(7-10) \\
3 \\
3 \\
1 \\
3 \\
3\end{array}$ & $\begin{array}{l}2 \\
48 \cdot 5(18-79) \\
0 / 2 \\
2(2-2) \\
9 \cdot 5(9-10) \\
0 \\
2 \\
0 \\
0 \\
1\end{array}$ & $\begin{array}{l}2 \\
59 \cdot 5(48-71) \\
1 / 1 \\
1 \cdot 5(1-2) \\
10(10-10) \\
2 \\
2 \\
0 \\
1 \\
2\end{array}$ & $\begin{array}{l}3 \\
54(43-78) \\
1 / 2 \\
1(1-2) \\
8(3-10) \\
2 \\
3 \\
1 \\
2 \\
3\end{array}$ & $\begin{array}{l}11 \\
55(21-80) \\
6 / 5 \\
2(1-3) \\
10(9-10) \\
0 \\
0 \\
0 \\
0 \\
0\end{array}$ \\
\hline
\end{tabular}

*Medians (range)

†Score 1 , less than nine years of school; score 2 , from nine to 11 years of school; score $3, \geqslant 12$ years of school.

$\ddagger$ Determined from Oldfield's scale. ${ }^{29} \mathrm{LSI}$ lenticulostriate infarcts; CAL = cortical associated lesion; AAIC $=$ anterior arm of the internal capsule; $M / F=$ males/females.

shortened evaluations of hemineglect and Anton Babinski syndrome were done during the acute stage.

Assessment of general intellectual abilities used the mini mental state examination (MMSE) ${ }^{30}$ with backward spelling of the word "rouge" (French translation of "red") and the French version of the Wechsler Adult Intelligence Scale (WAIS). ${ }^{31}$

Attentional state was assessed from visual and auditory reaction times. ${ }^{32}$

Assessment of language used the Boston diagnostic aphasia examination (BDAE) ${ }^{33}$ in patients with left-brain damage and in patients with right-brain damage demonstrating language disturbances on clinical evaluation. Phonemic paraphasia were rated separately. Individual performances were evaluated with cutoff scores suggested by BDAE and aphasia was diagnosed with BDAE criteria. ${ }^{33}$ In all patients, the following language investigations were carried out: oral comprehension with the shortened token test, ${ }^{34}$ buccofacial apraxia with Lehmkuhl's battery, ${ }^{35}$ lexicosemantic tasks, and syntactic abilities. For all these tests, individual performances of patients with aphasia were used and scores lower than 2 SDs from control means were considered as impaired. The lexicosemantic tasks included verbal fluency assessment (animals and fruits during one minute, and words starting with letter $\mathrm{C}$ during one minute), the similarities subtest of the WAIS, ${ }^{31}$ a test of categorisation of name and picture, ${ }^{36}$ semantic similarity judgments between 33 couples of words, and picture and colour naming. The oral picture naming test used 35 pictures $(10 \times 10 \mathrm{~cm})$ from the list of Snodgrass and Vanderwart ${ }^{37}$; the colour naming test was divided into two parts: naming 11 coloured dots and naming usual colour(s) of seven items given orally (banana, flag of communist countries, wedding dress, grapes, grass, tobacco, and melon). Syntactic abilities were investigated by the construction of 36 sentences divided into four parts (10 sentences-completion, 20 sentences-generation: 10 from a phrase and 10 from a word, seven sentences-construction) as carried out by $\mathrm{De}$ Lacy Costello and Warrington. ${ }^{38}$

Visuospatial hemineglect was clinically evaluated at the acute stage. Six weeks later, we added a cancellation test ${ }^{39}$ rated with the number of left minor right omissions, a line bisection test, ${ }^{40}$ and four simple drawing tasks rated on a $0-13$ point rating scale. One drawing test was performed by copying using Ogden's criteria ${ }^{18}$ and three on a verbal command condition: these were a clock, a daisy, and a human face (appendix). Hemineglect was diagnosed when more than one omission was observed on drawing tests, the bisection test, or the cancellation test.

Anosognosia for motor impairment and hemiasomatognosia intensity were rated during the acute stage and six weeks later with the two $0-3$ point Bisiach scales ${ }^{15}$ where 0 means no deficit and 3 means a severe deficit. The assessment of autotopognosia required the patient to name and point under verbal and imitation conditions to the six following items on the half of the body ipsilateral to the cerebral lesion: eyebrow, cheek, nostril, thumb, index, and ear.

Ideomotor apraxia was assessed with the battery of Lehmkuhl et al ${ }^{35}$ requiring realisation of 10 meaningless and 10 symbolic arm and manual movements under verbal and imitation conditions. Ideational apraxia was assessed with the battery of De Renzi et al. ${ }^{41}$

Short term memory was assessed with forward digit spans and the spatial spans subtest of the battery $144 .^{42}$ The span scores of patients were compared with those of controls.

Three-group comparisons (pure, cortical associated lesion, and control groups) were made by means of the Kruskall-Wallis $H$ test. Subsequently paired group comparisons were made with the Mann-Whitney U test. All tests were two sided; $p$ values $<0.05$ were regarded as statistically significant.

\section{Results}

No patient had Diagnostic and Statistical Manual of Mental Disorders III R criteria of dementia. ${ }^{43}$ MMSE scores for both groups of patients were significantly lower than controls and the two subgroups of patients did not differ significantly. Auditory and visual reaction times were not significantly different (table 2 ).

Four patients showed aphasia and all had left cerebral damage (two of the four patients 
Table 2 Median scores and ranges of MMSE, IQ, and median visual and auditory reaction times of controls and patients of the pure lenticulostriate infarct (LSI) and cortical associated lesion (CAL) groups

\begin{tabular}{lccll}
\hline & Pure LSI group & CAL group & Controls & p value \\
\hline $\mathrm{n}$ & 6 & 5 & 11 & \\
MMSE & $27 \cdot 5(29-26)$ & $26(10-30)$ & $29 \cdot 5(29-30)$ & $<0 \cdot 02$ \\
IQ & $93(83-113)$ & $90(79-99)$ & NP & - \\
$\begin{array}{l}\text { Mean visual and auditory } \\
\text { reaction times (ms) }\end{array}$ & $266(252-338)$ & $296(258-843)$ & $264(201-402)$ & NS \\
\hline
\end{tabular}

NP $=$ Not performed.

Table 3 Language assessment in aphasic patients of the pure lenticulostriate infarct (LSI) and cortical associated lesion (CAL) groups

\begin{tabular}{lccc}
\hline & Aphasic pure LSI group & Aphasic CAL group & Controls \\
\hline Severity & $3^{\star} / 4^{\star}$ & $2^{\star} / 2^{\star}$ & $5(5-5)$ \\
Token test & $29 / 34$ & $24^{\star} / 26^{\star}$ & 229 \\
Fluidity & $23^{\star} / 24^{\star}$ & $2^{\star} / 16^{\star}$ & $27(26-28)$ \\
Articulation & $6{ }^{\star} / 7$ & $11^{\star}$ & $7(7-7)$ \\
Buccolingual apraxia $(/ 20)$ & $18 / 20$ & $14^{\star}$ & $19 \cdot 5(18-20)$ \\
Phonemic paraphasia & $3^{\star} / 6^{\star}$ & $1 / 2^{\star}$ & 51 \\
Verbal paraphasia & $1 / 4^{\star}$ & $2^{\star} / 12^{\star}$ & 51 \\
Repetition & $17^{\star} / 26$ & $7^{\star} / 11^{\star}$ & $23 \cdot 7(20-26)$ \\
Reading & $32 / 40$ & $10^{\star} / 23$ & $38 \cdot 5(23-40)$ \\
Writing & $84 / 96$ & $17^{\star} / 40^{\star}$ & $83 \cdot 2(79-91)$ \\
\hline
\end{tabular}

Individual scores are given for aphasic patients; Control scores are means (range), the lowest corresponding to the suggested cutoff score. ${ }^{33}$

${ }^{\star}$ Patient's scores lower than cutoff scores.

Table 4 Performances of aphasic patients of the pure lenticulostriate infarct (LSI) and cortical associated lesion (CAL) groups and controls on lexicosemantic tasks and syntactic abilities

\begin{tabular}{lccl}
\hline & $\begin{array}{c}\text { Aphasic pure LSI group } \\
(n=2)\end{array}$ & $\begin{array}{c}\text { Aphasic CAL group } \\
(n=2)\end{array}$ & Controls \\
\hline Fluency: Animals & $12^{\star} / 17$ & $3^{\star} / 6^{\star}$ & $20 \cdot 6(4 \cdot 76)$ \\
Fruit & $10^{\star} / 15$ & $2^{\star} / 5^{\star}$ & $17(1 \cdot 89)$ \\
“C”" & $8^{\star} / 8^{\star}$ & $1^{\star} / 1^{\star}$ & $14(2 \cdot 45)$ \\
Naming (/33) & $26^{\star} / 27$ & $1^{\star} / 20^{\star}$ & $30 \cdot 4(2 \cdot 06)$ \\
Colour naming (/34) & $29^{\star / 31}$ & $1^{\star / 2} 7^{\star}$ & $32 \cdot 7(1 \cdot 56)$ \\
Semantic decision (/20) & $16^{\star} / 17^{\star}$ & $0^{\star} / 16^{\star}$ & $20(0)$ \\
Semantic categorisation & $40 / 40$ & $23^{\star} / 36^{\star}$ & $40(0)$ \\
Similarities subtest & $3^{\star} / 13$ & $0^{\star} / 2^{\star}$ & $17 \cdot 2(3)$ \\
Syntax BDAE & $5^{\star} / 6^{\star}$ & $1^{\star} / 4^{\star}$ & $7(0)$ \\
Sentences building (/20) & $12^{\star} / 19$ & $1^{\star} / 2^{\star}$ & $19 \cdot 3(0 \cdot 54)$ \\
\hline
\end{tabular}

Individual scores are given for aphasic patients; Control scores are means (SD).

$\star$ Patients' scores lower than cutoff scores.

Table 5 Median scores and ranges on gestural apraxia evaluation and on span tests of patients of the pure lenticulostriate infarct (LSI) and cortical associated lesion (CAL) groups and controls

\begin{tabular}{lllll}
\hline & Pure LSI group & CAL group & Controls & p value* \\
\hline Ideomotor apraxia (/40) & $40(38-40)$ & $35 \cdot 5(14-40) \dagger \ddagger$ & $40(38-40)$ & $<0 \cdot 01$ \\
Ideational apraxia (/14) & $14(14-14)$ & $12(10-13 \cdot 5) \ddagger$ & $14(14-14)$ & $<0 \cdot 05$ \\
Digit span & $6(4-9)$ & $4(4-6)$ & $5(4-8)$ & NS \\
Spatial span & $4(2-6)$ & $4(4-6)$ & $5 \cdot 5(4-6)$ & NS \\
\hline
\end{tabular}

^Kruskall-Wallis test.

†Significant difference between LSI and CAL groups (Mann-Whitney test).

$\ddagger$ Significant difference between CAL group and controls.

Table 6 Number of patients with aphasia, gestural apraxia, hemineglect, and AntonBabinski syndrome in the pure lenticulostriate (LSI) and cortical associated lesion (CAL) groups according to the side of lesion

\begin{tabular}{|c|c|c|c|c|}
\hline & \multicolumn{2}{|c|}{ Pure LSI group } & \multicolumn{2}{|c|}{$C A L$ group } \\
\hline & Left $B D$ & Right $B D$ & Left $B D$ & Right $B D$ \\
\hline $\mathbf{n}$ & 4 & 2 & 2 & 3 \\
\hline Aphasia & 2 & 0 & 2 & 0 \\
\hline Gestural apraxia & 0 & 0 & 2 & 1 \\
\hline \multicolumn{5}{|l|}{ Hemineglect } \\
\hline Acute stage & 0 & 0 & 0 & 3 \\
\hline \multirow{2}{*}{\multicolumn{5}{|c|}{ Anton-Babinski syndrome }} \\
\hline & & & & \\
\hline 6-8 weeks & 0 & 0 & 0 & $\begin{array}{l}3 \\
0\end{array}$ \\
\hline
\end{tabular}

Results from neuropsychological evaluation 6-8 weeks after stroke onset. The presence or absence of hemineglect and Anton-Babinski syndrome at the acute stage is also given. Left $\mathrm{BD}=$ patients with left-brain damage; right $\mathrm{BD}=$ patients with right-brain damage. with left-brain damage and pure lenticulostriate infarcts and both patients with left-brain damage of the cortical associated lesion group). Both aphasic patients with pure lenticulostriate infarcts had capsulostriate lesions that included the caudate nucleus and extended into the periventricular white matter. In the first patient, the overall profile of aphasia was close to that of a conduction aphasia except for the presence of hypophonia. The second patient did not fit any of the classic aphasic syndromes; he exhibited a mild speech reduction with verbal and phonemic paraphasias and arthric deformations. Both cases improved within three months with persistence of a mild word-finding difficulty and slight spontaneous speech reduction. Conversely, the two patients from the cortical associated lesion group exhibited a severe Broca's type aphasia, with initial mutism, evolving to agrammatism in one patient and to Broca's aphasia with anomia in the other.

In patients with aphasia in the pure lenticulostriate infarct group, data analysis showed mild severity of aphasia, sparing of oral comprehension, hypophonia, mild fluency loss, paraphasic errors mainly of phonemic type, and in one patient, an impairment of repetition (table 3). Lexicosemantic tasks were mildly disturbed, especially in one patient (table 4). At a syntactic level, sentence construction and BDAE syntax evaluation were slightly disturbed. All these performances were clearly less impaired than those of the two aphasic patients of the cortical associated lesion group.

Among the five patients with right-brain damage, three showed loss of exploration of the left hemispace with head and eye deviation during the acute stage. These three patients had a cortical associated lesion. Six weeks after onset, head and eye deviation had disappeared and one patient of the cortical associated lesion group showed hemineglect.

No autotopoagnosia was found; the AntonBabinski syndrome was present in the acute stage in three of the five patients with rightbrain damage: all of them had a cortical associated lesion. Six weeks after onset, the Anton-Babinski syndrome had resolved.

Gestural apraxia scores were significantly lower in the cortical associated lesion group (table 5).

Scores on span tests were not significantly different among patient subgroups (table 5).

Table 6 summarises the main results.

\section{Discussion}

Our study showed that: (1) pure left lenticulostriate infarcts on MRI may produce aphasia, (2) pure left lenticulostriate infarcts producing aphasia extended into the caudate nucleus and centrum semiovale; (3) gestural apraxia, hemineglect, and the Anton-Babinski syndrome were only found in patients with a cortical associated lesion.

Although the aim of our study was not to compare the sensitivity of CT and MRI evaluations, it confirms the superiority of MRI. ${ }^{44}$ 
Moreover, it strongly suggests that routine CT evaluation is not accurate enough to study relations between lenticulostriate infarcts and cognitive deficits. Disagreements between previous results ${ }^{11} 1314$ and ours might be explained by the use of MRI in our study. This led us to exclude three patients with a second infarct not seen on CT scans and located outside the ipsilateral middle cerebral artery territory, and to divide lenticulostriate infarcts into two subgroups based on the presence of an associated cortical lesion. Neuropsychological impairments were more severe in the five patients with a cortical associated lesion. Using CT criteria only, as in most previous studies, ${ }^{11} 14$ we would have included 14 patients, whereas only six had a pure lenticulostriate infarct and this would have led to an overestimation of neuropsychological disturbances in patients with pure lenticulostriate infarcts.

Aphasia of various types (Broca, Wernicke, conduction, amnesic, or thalamic ${ }^{2} 31314$ ) has been described in $30 \%$ to $80 \%$ of patients with left lenticulostriate infarcts. ${ }^{1113}$ In our study, the patients with Broca's aphasia had combined cortical lesions whereas the aphasia in patients with pure lenticulostriate infarct was less severe, close to conduction aphasia in one patient and unclassifiable in the other. Because MRI was required to reveal cortical involvement, it suggests that insufficient CT resolution could lead to erroneous correlations between the aphasia profile and the location of cerebral lesions.

Our two aphasic patients with pure lenticulostriate infarcts had capsulostriate lesions extending into the periventricular white matter, supporting the critical role of associated white matter damage in the pattern and severity of aphasia related to lesions of the striatal area. ${ }^{10}$ The role of capsulostriate structures and periventricular white matter in language processing remains uncertain. Disturbances in elaborate language tasks and slowing of speech initiation are often found in subcortical aphasia, and are often attributed to frontal lobe dysfunction. ${ }^{13}$ The absence of frontal lobe dysfunction and attentional deficit in the group with pure lenticulostriate infarcts ${ }^{24}$ argues against this hypothesis. Tasks requiring lexicosemantic processing were mildly disturbed suggesting a defective lexicosemantic access, as previously suggested. ${ }^{1644-46}$ Lexicosemantic access needs multiple processing that could require the integrity of the caudate nucleus, which receives multiple afferents from cortical associative areas. ${ }^{47-48}$ Lesions of the anterior arm of the internal capsule may interrupt thalamofrontal connexions and frontostriatothalamo frontal loops, ${ }^{49}$ the role of the last being suggested by a SPECT study of aphasia related to lesions of the left thalamus. ${ }^{45}$

Visuospatial hemineglect has been reported in $30 \%$ of patients with right subcortical strokes $^{19}$ and in $20 \%$ of patients with lenticulostriate infarcts. ${ }^{13}$ In our study, patients with hemineglect or Anton-Babinski syndrome had a combined cortical infarct on MRI. The absence of hemineglect in patients with pure lenticulostriate infarcts might be explained by sparing of thalamoparietal connections. ${ }^{8}$

Only patients of the cortical associated lesion group had significantly lower scores on assessment of gestural apraxia. This result disagrees with those of CT documented subcortical lesions, ${ }^{20-22}$ which suggest that gestural apraxia is found in capsulostriatal lesions with a lower frequency and with a milder severity than in cortical lesions. This low frequency and the small size of our sample could explain our negative result. It suggests a critical role for the combined cortical lesion, however.

In the group of patients with cortical involvement, neuropsychological deficits were clearly more severe. This could be due to the greater size of the cerebral lesion or to the critical role of the cortical structures in those neuropsychological functions. Our study cannot discriminate between these two hypotheses as both factors were confounded.

Previous studies with functional imaging emphasised the role of cortical hypoperfusion in patients with aphasia or hemineglect due to capsulostriatal lesions documented by CT scan. ${ }^{450}$ These studies suggested a cortical deafferentation but our results suggest that a cortical infarct not seen on CT might also account for the cortical hypoperfusion. Cortical metabolism has been evaluated in the present patients with pure capsulostriate infarcts using single photon emission CT and these results will be reported later.

Our results suggest that pure lenticulostriate infarcts usually produce mild neuropsychological changes and that more severe aphasia, especially of the Broca's type and other neuropsychological deficits like hemineglect and gestural apraxia are mainly due to associated cortical lesions. These results have to be confirmed by further studies assessing a larger number of patients. Our study supports the need for a precise radiological analysis by MRI, as it shows associated lesions that could account for the variability of clinicoanatomical correlations usually reported.

Appendix: scoring of drawings tests on verbal command condition

\begin{tabular}{llll}
\hline Score & Clock & Daisy & Human face \\
\hline 0 & $\begin{array}{l}\text { No omission } \\
\text { One quarter } \\
\text { vacant }\end{array}$ & $\begin{array}{l}\text { No omission } \\
\text { One contralesional } \\
\text { missing petal }\end{array}$ & $\begin{array}{l}\text { No omission } \\
\text { hair missing }\end{array}$ \\
2 & $\begin{array}{l}\text { Half a clock } \\
\text { vacant }\end{array}$ & $\begin{array}{l}\text { Partially } \\
\text { completed on the } \\
\text { contralesional side } \\
\text { Contralesional } \\
\text { half completely } \\
\text { missing }\end{array}$ & $\begin{array}{l}\text { Contralesional ear } \\
\text { missing }\end{array}$ \\
3 & $\begin{array}{l}\text { Missing } \\
\text { contralesional eye }\end{array}$ \\
4 & & $\begin{array}{l}\text { Half of face } \\
\text { completely missing }\end{array}$ \\
\hline
\end{tabular}

We thank M Houdart, V Petit, N Pécheux, S Van Bogaert, and $B$ Debachy for their technical assistance in the neuropsychological assessment, $\mathrm{H}$ Petit, A Destée, and $\mathrm{Ph}$ Kassiotis who allowed us to investigate some of their patients, $F$ Ghawché, F Mounier-Vehier, and P Rondepierre for their help, and C Onckelynck for reviewing the final version of the help, and $C$ Onckelynck for reviewing the final version of the
manuscript. The work was supported in part by grants from manuscript. The work was support
the Faculte de médecine de Lille. 
1 Cambier J, Elghozi D, Strube E. Hémorragie de la tête du noyau caudé gauche. Rev Neurol 1979;135:763-74.

2 Brunner RJ, Kornhuber HH, Seemuller E, Suger G, Wallesch $C W$. Basal ganglia participation in language pathology. Brain Lang 1982;16:281-99.

3 Damasio AR, Damasio H, Rizzo M, Varney N, Gersh F Aphasia with non hemorrhagic lesions in the basa ganglia and internal capsule. Arch Neurol 1982;39. ganglia

4 Perani D, Vallar G, Cappa S, Messa C, Fazio F. Aphasia and neglect after subcortical stroke. Brain 1982;110: 1211-29.

5 Adams H, Damasio H, Putnam S, Damasio AR. Middle cerebral artery occlusion as a cause of isolated subcortical cerebral artery occlusion as a cause
infarction. Stroke 1983;14:948-52.

6 Wallesch CW, Kornhuber HH, Brunner RJ, Kunz T, Hollerbach B, Suger G. Lesions of the basal ganglia thalamus and deep white matter: differential effects on language functions. Brain Lang 1983;20:286-304

7 Puel M, Demonet JF, Cardebat D, et al. Aphasies sous-corticales. Rev Neurol 1984;140:695-710.

8 Decroix JP, Graveleau P, Masson M, Cambier J Infarction in the territory of the anterior choroida artery. Brain 1986;109:1071-85.

9 Olsen TS, Bruhn P, Oberg GE. Cortical hypoperfusion as a possible cause of "subcortical aphasia". Brain 1986 109:393-410.

10 Alexander MP, Naeser MA, Palumbo CL. Correlations of subcortical CT lesion sites and aphasia profiles. Brain 1987;110:961-91.

11 Levine $R$, Lagreze $H$, Dobkin J, Turski P. Large subcortical hemispheric infarctions. Arch Neurol 1988;45:1074-7.

12 Caplan L, Schmahmann J, Kase C, et al. Caudate infarcts. Arch Neurol 1990;47:133-43.

13 Weiller C, Ringelstein B, Reiche W, Thron A, Buell U. The large striatocapsular infarct. A clinical and pathological entity. Arch Neurol 1990;47:1085-91.

14 Donnan G, Bladin P, Berkovic S, Longley W, Saling M. The stroke syndrome of striatocapsular infarction. Brain 1991;114:51-70.

15 Bisiach E, Perani D, Vallar G, Berti A. Unilateral neglect: personal and extrapersonal. Neuropsychologia 1986;24: 159-67.

16 Damasio AR, Damasio H, Chang Chui H. Neglect following damage to frontal lobe or basal ganglia. Neuropsychologia 1980;18:123-32.

17 Hier DB, Mondlock J, Caplan LR. Behavioral abnormalities after right hemisphere stroke. Neurology 1983;33: 337-44.

18 Ogden JA. Anterior-posterior interhemispheric differences in the loci of lesions producing visual hemineglect. Brain Cogn 1985;4:59-75.

19 Vallar G, Perani D. The anatomy of unilateral neglect after right hemisphere stroke lesions. Neuropsychologia 1986:5:609-22

20 Agostini E, Coletti A, Orlando G, Tredici G. Apraxia in deep cerebral lesions. I Neurol Neurosurg Psychiatry 1983;46:804-8

21 Kertesz A, Ferro JM. Lesion size and location in ideomotor apraxia. Brain 1984;107:921-33

22 Basso A, Della Sala S. Ideomotor arising from purely deep lesion. $\mathcal{F}$ Neurol Neurosurg Psychiatry 1986;49:458

23 Mendez M, Adams N, Lewandowski K. Neurobehavioural changes associated with caudate lesions. Neurology 1989;39:349-54.

24 Godefroy O, Rousseaux M, Leys D, Destée A, Scheltens $\mathrm{Ph}$, Pruvo JP. Frontal lobe dysfunction in unilateral lenticulo-striate infarcts: prominent role of cortical lenticulo-striate infarcts: prominent
lesions. Arch Neurol 1992;49:1285-9.

25 Anderson SW, Damasio H, Tranel D. Neuropsychological impairments associated with lesions caused by tumor or stroke. Arch Neurol 1990;47:397-405.

26 Lazorthes G, Gouazé A, Salamon G. Vascularisation et circulation de l'encéphale. Paris: Masson, 1976.

27 Ringelstein EB, Zeumer H, Angelou D. The pathogenesis of strokes from internal carotid artery occlusion. Stroke 1983;14:867-75

28 Fazekas F, Chawluk JB, Alavi A, Hurtig MI, Zimmerman RA. MR signal abnormality at $1.5 \mathrm{~T}$ in Alzheimer dementia and normal aging. Am $\mathcal{F}$ Neuroradiol 1987;8: 421-6.

29 Oldfield RC. The assessment and analysis of handedness: the Edinburgh inventory. Neuropsychologia 1971;9: 97-113

30 Folstein MF, Folstein SE, McHugh PR. "Mini-mental state": a practical method for grading the cognitive state of patients for the clinician. $f$ Psychiat Res

31 Wechsler D. Echelle d'intelligence de Wechsler pour adultes. Paris: Editions du Centre de Psychologie Appliquée,

32 Leclercq M, Chipp P, Blandel A, et al. A simple reaction times set. European symposium on microcomputers in neuropsychological assessment and rehabilitation, Strasbourg, 1988.

33 Mazaux JM, Orgogozo JM, Henry P, Loiseau P. Troubles du langage au cours des lésions thalamiques. Etude par le test de Goodglass et Kaplan. Rev Neurol 1979; 135:59-64.

34 De Renzi E, Faglioni P. Normative data and screening power of a shortened version of the token test. Cortex 1978;14:41-9.

35 Lehmkuhl G, Poeck K, Willmes K. Ideomotor apraxia and aphasia: an examination of types and manifestations of apraxic symptoms. Neuropsychologia 1983;21:199-212.

36 Bachy $\mathrm{N}$. Batterie d'examen des troubles en dénomination. Bruxelles: Editest, 1989.

37 Snodgrass JG, Vanderwart M. A standardized set of 260 pictures: norms for name agreement, image agreement, familiarity and visual complexity. F Exp Psychol 1980; 6:174-215

38 De Lacy Costello A, Warrington EK. Dynamic aphasia: the selective impairment of verbal planning. Cortex 1989;25:103-14.

39 Gauthier L, Dehaut F, Joanette Y. The Bells Test: a quantitative and qualitative test for visual neglect. International fournal of Clinical Neuropsychology 1989;11: 49-53.

40 Schenkenberg T, Bradford DC, Ajax ET. Line bisection and unilateral visual neglect in patients with neurological impairment. Neurology 1980;30:509-17.

41 De Renzi E, Pieczuro A, Vignolo LA. Ideational apraxia: a quantitative study. Neuropsychologia 1968;6:41-52.

42 Signoret JL. La Batterie d'Efficience Mnésique: BEM 144. Paris: Elsevier, 1991

43 American Psychiatric Association. Diagnostic and statistical manual of mental disorders. 3rd edn Revised. Washington, DC: APA, 1980

44 De Witt LD, Grek AJ, Buonanno FS, Levine DN, Kistler JP. MRI and the study of aphasia. Neurology 1985; 35:861-5.

45 Rousseaux M, Steinling M, Griffié G, et al. Corrélations de l'aphasie thalamique avec le débit sanguin cérébral. Rev Neurol 1990;146:345-53.

46 Demonet JF, Cardebat D, Angibaud G, et al. Brain and language: correlative study between MRI and linguistic symptoms in aphasic patients. Wien: PanEuropean Neurological Society of Neurology 1991:SC A5 03.

47 Yeterian E, Van Hoesen GW. Cortico-striate projections in the rhesus monkey: the organization of certain cortico-caudate connections. Brain Res 1978;139:43-63.

48 Mesulam MM. Large-scale neurocognitive networks and distributed processing for attention, language and memdistributed processing for attention,
ory. Ann Neurol 1990;28:597-613.

49 Alexander G, De Long M, Strick P. Parallel organization of functionally segregated circuits linking basal ganglia and cortex. Annu Rev Neurosci 1986;9:357-81.

50 Metter EJ, Riege WH, Hanson WR, et al. Comparison of metabolic rates, language and memory in subcortical aphasias. Brain Lang 1983;19:33-47. 